Tjalling C. Koopmans Research Institute

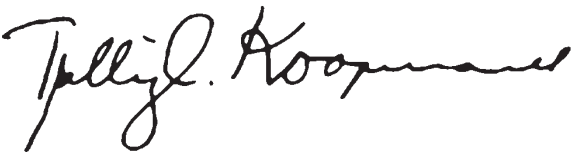

Discussion Paper Series nr: 03-18

\title{
Survivor: The Role of Innovation in Firms' Survival
}

Elena Cefis

Orietta Marsili 


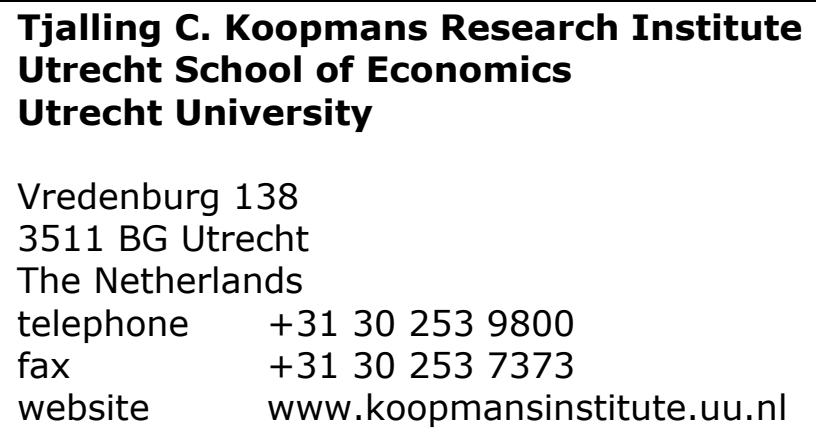

The Tjalling C. Koopmans Institute is the research institute and research school of Utrecht School of Economics.

It was founded in 2003, and named after Professor Tjalling C. Koopmans, Dutch-born Nobel Prize laureate in economics of 1975.

In the discussion papers series the Koopmans Institute publishes results of ongoing research for early dissemination of research results, and to enhance discussion with colleagues.

Please send any comments and suggestions on the Koopmans institute, or this series to P.vanDriel@econ.uu.nl ontwerp voorblad: WRIK Utrecht

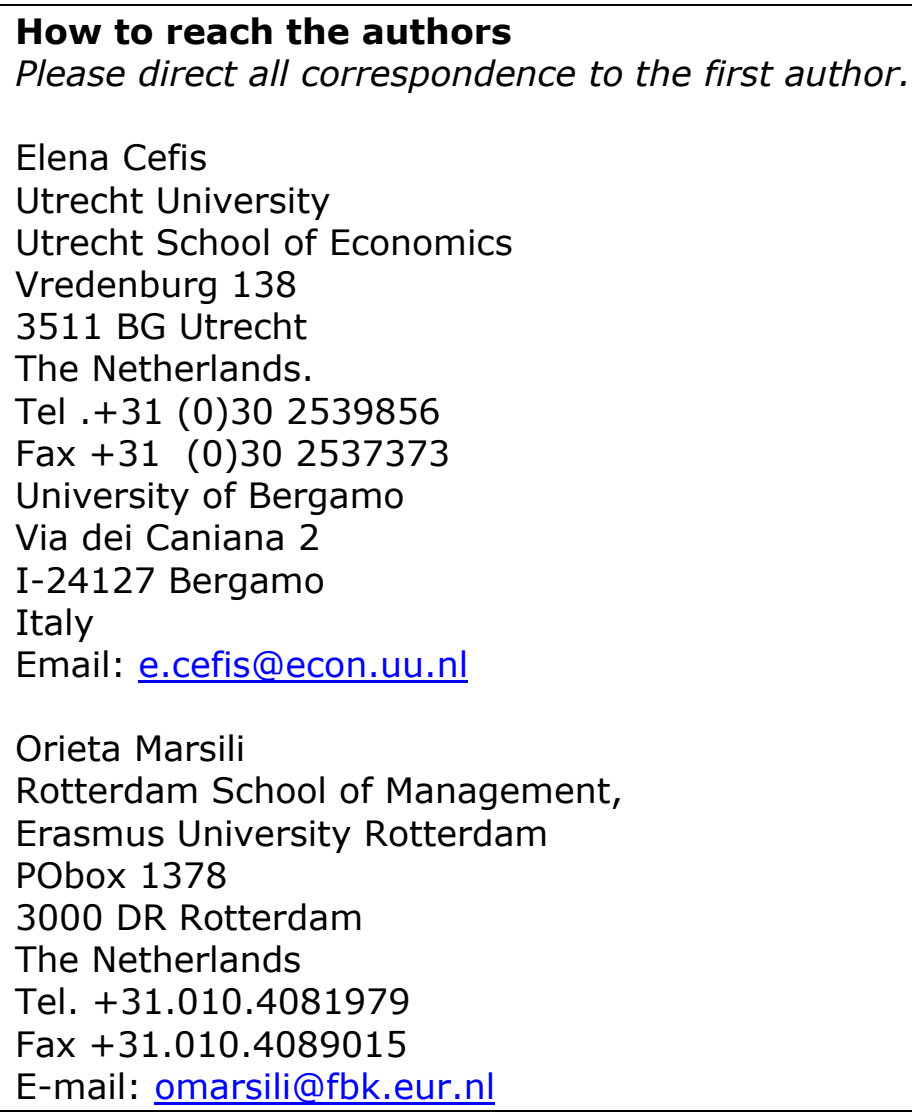

This paper can be downloaded at:

http://www.koopmansinstitute.uu.nl 


\title{
Survivor: The Role of Innovation in Firms' Survival*
}

\author{
Elena Cefis ${ }^{\mathrm{a}}$ \\ Orietta Marsili ${ }^{b}$ \\ a Utrecht School of Economics, Utrecht University \\ University of Bergamo \\ ${ }^{b}$ Rotterdam School of Management \\ Erasmus University
}

November 2003

\begin{abstract}
This paper explores the relationship between innovation and the survival of manufacturing firms in the Netherlands. The determinants of the survival probability of a firm, traditionally identified in the size and age of a firm, are extended to include the ability of a firm to introduce an innovation in the market. The empirical analysis combines economic and demographic data from the Business Register of the population of firms active in the Netherlands with data on innovation derived from the second Community Innovation Survey. The survival probability of a firm is estimated by using a non-parametric approach: Transition Probability Matrices were calculating over different time periods. We observe that, in general, innovation has a positive and significant effect on firms' survival that increases as time lengthens. Furthermore, our results confirm that small and young firms are those most exposed to the risk of exit, but at the same time those that benefit most of innovation to survive in the market, especially in the longer term.
\end{abstract}

Keywords: Firm Survival; Innovation; Firms Exit; Transition Probability Matrices

JEL classification: L11; O30; D21; C14; L25

\section{Acknowledgements}

We wish to thank the seminar participants at Nuffield College (University of Oxford), the Tinbergen Institute (University of Amsterdam), Amsterdam Institute for Advanced Labour Studies and the 2003 Meeting of the European Society of Population Economics for valuable comments, and Nigel Stuttard at National Statistics for providing the NES data. Financial support from the Leverhulme Trust project "The labour market consequences of technical and structural change" is gratefully acknowledged. Please direct all correspondence to the first author.

\footnotetext{
* The empirical part of this research has been carried out at the Centre for Research of Economic Microdata at Statistics Netherlands. The views expressed in this paper are those of the authors and do not necessarily reflect the policies of Statistics Netherlands. We would like to thank the participants at the conference "What do we know about innovation?" in honour of Keith Pavitt, University of Sussex, in particular David Mowery for his discussion, Anita McGahan and Ammon Salter for comments and suggestions. We are also grateful to Isa Marchini and other participants at the conference RENT XVIIResearch in Entrepreneurship and Small Business, University of Lodz for helpful comments. Support by the University of Bergamo (grant ex 60\%, n. 60CEFI03, Dep. Of Economics) is gratefully acknowledged.
} 


\section{Introduction}

This paper explores the relationship between innovation and the survival of firms using demographic data on manufacturing firms active in the Netherlands and the Community Innovation Survey. The empirical literature has highlighted in the last two decades the high degree of turbulence, due to entry and exit dynamics, that characterised most industries. A large proportion of new firms exit the industry within few years after entry as well as established firms are subject to shakeouts. The growth and survival of firms will depend on their ability to successfully adapt their strategies to changing environments. In such environments, innovation creates variety of competitive positions and enhances a firm's potential to succeed in the market. This effect is important for new enterprises as well as established firms. Innovation may increase the chance of survival of new firms allowing successful niches strategies. At the same time, innovation is necessary for well-established firms to deal with new and emerging or 'disruptive' technologies (Christensen, 1997).

A number of studies have looked empirically at the factors that influence the probability of firms to survive in the market. At the firm level, these factors have been traditionally identified in the size and age of the firm, both increasing survival probability (Dunne and Hughes, 1994). At the industry level, the characteristics of demand, such as market size and growth rates (Mata and Portugal, 1994), the characteristics of technology (Audretsch, 1995) and the life cycle (Agarwal and Audretsch, 2001) have been found to be important determinants of the survival probability. These studies, however, focus either on structural features of the firm or on differences in the external environment. Only few empirical studies have looked at the role of innovation within the firm in shaping the survival probability of it.

In this paper we explore how the probability of survival is influenced by innovation. The availability for the Netherlands of two harmonised and comprehensive micro-economic data sets collected by the Central Bureau of Statistics (CBS) - one on innovation (Community Innovation Survey) and the other reporting monthly the date of entry and exit of firms (Business Register) - allowed us to link innovation and survival at the firm level, for a large sample of manufacturing firms.

Confirming previous research, we find that the demography of firms is influenced by firm size and age. The firms most likely to exit and disappear from the market are small and young firms. The effect of size and age is shaped, however, by 
the extent firms do engage in innovative activities. In general, we find that the ability to innovate increase survival probabilities for all firms and across most industrial sectors. We label this as the 'survival premium' associated with innovation. In particular, this premium is highest for small and young firms: indeed, for those firms that are in the greatest danger of failure. In fact, small, young firms who innovate have 23 per cent greater change of surviving than those who do not innovate.

The paper is structured as follows. Section 2 discusses theoretical approaches and empirical studies on the determinants of firm survival. The data used in the empirical analysis is described in Section 3 and the methodology applied for the estimation of the survival probability in Section 4. We illustrate the results of the analysis in Section 5. Section 6 is the conclusions.

\section{Theoretical and Empirical background}

Schumpeter (1942) pointed out the fundamental role that innovation plays for the survival of firms competing in the market. The introduction of new combinations leads to a process of "competition which commands a decisive cost or quality advantage and which strikes not at the margins of the profits and the outputs of the existing firms but at their foundations and their very lives" (Schumpeter, 1942, p. 84). Recently Baumol (2002) has reaffirmed the importance of innovation as the vital activity of a firm: “...under capitalism, innovative activity...becomes mandatory, a life-and-death matter for the firm and innovation has replaced price as the name of the game in a number of important industries" (Baumol, 2002, p. 1). Despite this strong emphasis on innovation as an imperative for the survival of firms, there are yet few empirical studies that have linked the innovativeness of the firm to its own survival.

Different approaches in economics have stressed two factors underlying the decision of a firm to exit the market (Audretsch, 1997): one is the gap between firm size and the minimum efficient scale, another is the selection mechanism of heterogeneous firms. The former approach characterise the mainly empirical tradition of cross-sectoral studies in industrial economics (Scherer, 1980). According to this approach the survival probability should be lower in presence of economics of scale in an industry. The latter approach is shared by equilibrium models of industrial competition based on Jovanovic's (1982) theory of noisy selection. In Jovanovic's model, firm dynamics depend on the learning process by which firms discover and 
adapt to their level of efficiency, given the existence of asymmetries in efficiency and imperfect information. This model predicts that the hazard rate of a firm decreases with current size (conditional on age) as well as with firm age.

These predictions are consistent with the evidence from early empirical studies in industrial economics (Evans, 1987; Hall, 1987). Empirical studies have showed that the probability of survival increases with age and size of the firm, although at a decreasing rate. A positive interactive effect of age and size on firm survival has also been observed: the probability of survival increases with age more rapidly for large firms and vice versa. In addition, studies that have focused on the post-entry performance of new firms have found that the probability of survival increases with the size of the new firm at the time of entry.

As for the non linear effect observed between age and the probability of survival, other studies estimating the hazard function of different cohorts of entrants suggest that the relationship between the two variables is a complex one (Mata and Portugal, 1994; Mata, Portugal and Guimaraes, 1995). In some cases the hazard rate decreased over time linearly; in others it increased significantly soon after the entry of a firm, before turning to decrease more or less linearly. Therefore, while there is a positive relationship between survival probability and firm age at least for older firms, the relationship is not definite for younger firms.

The importance of innovation for firm survival has been explored in a model of industrial competition proposed by Ericson and Pakes (1995), which extended Jovanovic's model of 'passive learning'. The model allows for a process of exploration by firms, or 'active learning': by investing in research and development, firm actively accelerate their learning process. This investment creates uncertainty of results and endogenous asymmetries among firms. As a result, less profitable firms will exit the market. The model predicts that high rates of innovation in a sector, as associated with high uncertainty, lead to high exit rates. Ericson and Pakes's model of selection assumes that exit is the outcome of an optimising decision process. In contrast, Nelson and Winter (1982) interpret the selection mechanism as an evolutionary process which transforms existing asymmetries into differential rates of growth and survival. These asymmetries reflect the heterogonous distribution of knowledge and capabilities across firms. In addition, the distribution varies over time as outcome of the innovation process. Through innovation, firms seek to improve 
their relative position in the distribution and their chance of success in the competition process.

The evolutionary approach, following Nelson and Winter's model, stresses that the conditions for survival differ across technologies and sectors. It distinguishes alternative technological regimes, typically characterised as an "entrepreneurial regime" in which new firms have an innovative advantage compared to established firms and a "routinised regime" in which the advantage is inverted between the two. More recently, the empirical literature in industrial economics has examined the effects of industry specific factors on firm survival (Audretsch 1998). The survival probability varies across sectors. These differences are stable over time especially when compared to more volatile entry rates. This evidence has been interpreted on the grounds of the existence of barriers to survival acting more effectively than barriers to entry (Geroski, 1995). These barriers have been related to the nature of technology, the presence of scale economies and the rate of demand growth in industrial sectors.

Audretsch (1995) in particular has linked technological conditions to the survival probability of new firms. In his results, more innovative industries display lower probability of survival for new firms within limited period after entry, while they display higher probability of survival for firms that have survived a certain number of years ( 8 years in the cited study) after entry. Similar effects are also observed for the level of innovation of small firms in the industry, which approximated the "entrepreneurial" nature of the innovation regime. This evidence thus suggests that technological regimes are important determinants of survival probability and that these effects may vary according to the age of the firm. That is, innovation in an industrial sector, and especially an "entrepreneurial regime", are associated with high survival probability of young firms and low survival probability of older firms.

Despite the role attributed to the innovative environment for a firm's survival, there is very little empirical evidence on the relationship between the probability of survival and the innovative activities carried out within the firm. In this respect, management studies have stressed the strategic role of innovation for firm survival. Christensen, Suarez and Utterback (1998) showed that the combination of technological and market strategies are important predictors of a firm's probability of survival. In particular, they explored how different types of innovations, architectural and components, and the timing of entry into a new market influence the survival probability at different stages of evolution of a new technology, before and after the 
emergence of a dominant design. These studies, however, are based on specific industries and datasets and do not allow to establish more general properties.

The purpose of this study is to investigate how innovative activities within the firm influence the survival probability of it. In doing so, we also take into account the previous findings from the literature. In particular, we control for the influence of firm size and age on the effects of innovation on firm survival. Furthermore, in order to account for the specific nature of technology we examine the differences in these effects across sectors.

\section{Data}

The analysis uses two micro-economic databases collected from the Central Bureau of Statistics Netherlands (CBS): the Business Register database and the Second Community Innovation Survey (CIS-2) in the Netherlands. Using these datasets, we were able to integrate, at the firm level, comprehensive data on innovation and exit. The Business Register database consists of all the firms registered for fiscal purposes in the Netherlands in the period 1993-1998. The database reports employment statistics, sector of activity at 6-digit of the Standard Industrial Classification and the date (expressed in month) a firm was first included in the database and the date a firm last appeared in the database. Because of the comprehensive nature of the Business Register, these dates can be considered as close approximations of the actual date of entry and exit of a firm in the population. From the Business Register we selected all manufacturing firms present in the database at the year 1996. These are 61,177 firms. This population includes also firms with zero employees, referred to as self-employment. We selected the year 1996 for comparison with the CIS-2.

On the basis of the Business Register we build a number of variables that express the structural characteristics of a firm and that we use as control variables in the analysis of survival and innovation. First, using the date of entry into the database we calculated the age of a firm at 1996 according to 4 age classes: 0-4 years old; 5-10 years old; and more than 10 years old. The age 0 identifies those firms that have entered during the year 1996. We also classify each firm in four size classes according to the number of employees at 1996: 0-9 employees, 10-49 employees; 50-199 employees; and 200 and more employees. Each firm is also assigned a sector of 
activity at 2-digit level SIC code. The Tobacco sector was excluded from the analysis because of the limited number of observations, namely only 13 firms. For the technological proximity of the sectors and the high degrees of diversification of the firms active in these sectors, the firms belonging to the electrical-electronic field were aggregated in a single class. This includes computers (SIC 30), electrical equipment (SIC 31) and telecommunication equipment (SIC 32) (see Table I of the Appendix for the definition of the sectors).

Finally, we use the Business Register database to identify the date in month a firm exit the population and estimate the survival probability. The exit date ranges from January 1996 to June 2000. The dataset thus covers 55 months of possible existence of a firm. For each month, we built a dummy variable that was set equal to 1 if the firm existed in the database and 0 if not.

The second database we use in the analysis is the Second Community Innovation Survey (CIS-2) in the Netherlands. The CIS-2 was held in 1996 and provides information on the innovation process of firms in the Netherlands for the period 1994 - 96. The survey was carried out in the entire private sectors for firms with at least 10 employees. This was a stratified random sample drawn from the Business Register database at 1996, according to size class, region and industrial sector at 2-digit level of the SIC code. In manufacturing, the number of respondents to the CIS-2 was 3,299 firms, with a response rate of 71 per cent. On the basis of the CIS-2 dataset, we classified these firms into innovators and non-innovators. An innovator is defined as a firm that has introduced in the period 1994 - 1996 either a product innovation or a process innovation. These two CIS variables reflect the subjective perception of "being an innovator" by the respondents. Therefore our definition of innovators is broad and encompassing, and therefore leading to an underestimation of the effects of innovation on the survival probability.

Of the respondents to the survey 3,275 firms could be matched with the firms from the Business Register at 1996. Our analysis thus excludes 14 companies that could not be linked to the Business Register dataset. These are large diversified companies for which the unit of observation in the CIS survey does not coincide with the unit of observation in the Business Register. This implies that the survival probabilities of large, old and innovative firms are underestimated.

In sum, by using the CIS-2 database we were able to separate two sets of firms, innovators and non-innovators, for a random sample of firms drawn from the Business 
Register of all manufacturing firms in the Netherlands at 1996. Having determined the age class, size class, industrial sector and date of exit of firms from the entire population of the Business Register, we could then compare the survival probability of innovators and non-innovators by controlling for age, size and sector, (also in comparison to the general conditions of survival in the overall population).

\section{Methodology}

We use a non-parametric approach based on Transition Probability Matrices to analyse the survival probabilities among different groups of firms. We measure survival probability as the firm probability of remaining in the state in which the firm actually exists, while the probability of exiting the market is given by the probability to go from the state of existence to the one of non-existence.

Among a finite population of firms (firms that actually existed when the second wave of CIS was collected, namely 1996), at each point in time (after 1996) there is a cross-section distribution of firms that do exist and do not exist anymore. The idea is to describe the evolution of these distributions over time, which will allow us to analyse intra-distribution mobility of firms supplying the information about the firm's relative situation and its movement over time (Cefis, 2003).

To study the evolutions of the distributions is necessary to hypothesise a law of motion for the cross-section distributions in a more formal structure.

Let $F_{t}$ denote the distribution of firms at time $t$; and let us describe $\left\{F_{t}\right.$ : integer $t\}$ 's evolution by the law of motion:

$$
F_{t+m}=P \cdot F_{t}
$$

were $P$ maps one distribution into another, and tracks where points in $F_{\mathrm{t}}$ end up in $F_{t+m}$. Equation (1) is a useful first step for analysing the dynamics of $\left\{F_{\mathrm{t}}\right\}$. Operator $P$ of equation (1) can be approximated by assuming a finite state space for firms $S=\left\{s_{1} s_{2} \ldots s_{\mathrm{r}}\right\}$, where $s_{i}(i=1, \ldots, r)$ are the possible states. In this case $P$ is simply a Transition Probability Matrix (TPM). $P$ encodes the relevant information about mobility and persistence of firms within the cross section distributions.

Therefore, the one-step transition probability is defined by:

$$
p_{i j}=P\left(X_{t+m}=j \mid X_{t}=i\right)
$$

with $t=1996,1997, \ldots, 1999$ and $m=24,30,36$, and 42 months. 
The Transition Probability Matrix $\mathbf{P}$ is the matrix with $p_{i j}$ as elements measuring the probability of moving from state $i$ to state $j$ in one period. In this analysis, the states are identified by the condition of existence of the firm.

The focus of our analysis is on the probabilities of survival of firms. Therefore, we compute two state TPMs where the first state is defined as the non-existing state in which firms are non-active in the market (in fact they have left the market), while the second one is defined as the existing state in which firms are actually present in the market. This two state TPM offers useful information for analysing survival since it measures the probability that a firm remains in the existence state or that it goes from a state of existence to the state of non-existence in one period.

Let $i$ be the state of firm existence, and $j$ the one of non-existence, the two states Transition Probability Matrix is given by:

$$
P\left[X_{t}=j \mid X_{t-m}=i\right]=\left[\begin{array}{cc}
p & 1-p \\
1-q & q
\end{array}\right] .
$$

According to our definition, $q$ is the probability of survival, while $1-q$ is the probability to exit the market. In the following, we will concentrate only on $q$, not even reporting the estimates of the other probabilities.

TPMs are computed on four different period lengths (for different $m$ ): i) 24 months; ii) 30 months; iii) 36 months; iv) 42 months. These different transition periods allow to capture the dynamics of the survival probability of the firms and to study how it evolves over time.

It is worth noting that in order to perform the persistence analysis we have assumed that firms are homogeneous. In this context a way to take into account heterogeneity among firms, due to being in different sectors or having different size or age, is dividing the overall sample in sub-samples according to industrial classifications and size and age classes. Nevertheless, in the sub-samples firms are supposed to be homogeneous and there is no way, using this methodology, to control for heterogeneity at the firm level ${ }^{1}$.

We have conducted the analysis over the entire sample and also dividing the sample according to size classes, age classes, and to the industrial classification. Furthermore, we have performed our analysis considering initially these firm-specific

\footnotetext{
${ }^{1}$ An extension of this analysis could be to test for endogenous group heterogeneity.
} 
characteristics separately, in order to identify what are the effects only of size, age and technological specificities on the survival probability. Successively, we have repeated the analysis controlling contemporaneously for these firm characteristics jointly.

In order to test whether the difference between two estimated probabilities were statistically significant, we applied the following test.

Let $P_{1}$ and $P_{2}$ be the survival probabilities estimated in the samples of size $n_{1}$ and $n_{2}$ (for example the survival probabilities between innovators and non-innovators in the CIS) drawn from respective populations having probabilities $p_{1}$ and $p_{2}$. The null hypothesis is that there is no difference between the survival probabilities of the populations, that is $H_{0}: p_{1}=p_{2}$, and thus the samples are really drawn from the same population with survival probability $p$. The test statistics is the difference in the estimated probabilities: $P_{1}-P_{2}$. Given the fact that the size of our samples is sufficiently large (with at least $n>80$ ), under the null hypothesis, we have that the standardised variable

$Z=\frac{P_{1}-P_{2}-0}{\sigma_{P_{1}-P_{2}}}$ is approximately distributed $\mathrm{N}(0,1)$, where

$\sigma_{P_{1}-P_{2}}=\sqrt{\frac{p_{1}\left(1-p_{1}\right)}{n_{1}}+\frac{p_{2}\left(1-p_{2}\right)}{n_{2}}}$

Given that $p_{1}$ and $p_{2}$. are unknown and for the null hypothesis $p_{1}=p_{2}=p$, the estimator of $\sigma_{P_{1}-P_{2}}$ is

$$
S_{P_{1}-P_{2}}=\sqrt{P(1-P)\left(\frac{1}{n_{1}}+\frac{1}{n_{2}}\right)}
$$

where $P$ is the estimator of the survival probability of the population given by the arithmetic weighted average of $p_{1}$ and $p_{2}$ :

$P=\frac{n_{1} P_{1}+n_{2} P_{2}}{n_{1}+n_{2}}$

We have tested the differences in the survival probabilities of different sub-groups of firms and the test results are reported in Tables II and III of the Appendix. 


\section{Results}

\subsection{Innovators versus non-innovators}

In this section we compare the general characteristics of the different samples we have used in the analysis. Table 1 shows the descriptive statistics of the number of employees in the different samples and Table 2 the corresponding survival probabilities for the different transition periods. First, we observe that the threshold of 10 employees is an important one. As shown in Table 1, this threshold excludes about $4 / 5$ shares of all the firms in the population of the Business Register (BR). The large majority of firms are small or even very small firms (considering that the BR also includes firms with 0 employees). These very small firms are not included in the innovation surveys of the European Union. Indeed the CIS is a stratified random sample of firms with at least 10 employees. ${ }^{2}$ Furthermore, within the threshold of 10 employees, the survey tends to capture the largest firms. The average size of firms within the CIS is equal to 117.2 employees, while the average size of firms in the BR with more than 10 employees but without the CIS is 58.1 (see Table 1). In addition, in the CIS, innovative firms tend to be larger than non-innovative firms: their average size is respectively equal to 139.5 and 78.5 employees.

\section{Insert Table 1}

In Table 2, the first two rows show the importance of the threshold of 10 employees for the survival probability. There is a relevant difference in the probability between the entire Business Register (BR) and the BR with more than 10 employees. The former is lower than the latter of about 0.08 (equal to 9.8 per cent). This difference is statistically significant at 1 per cent level, independent of the transition period. Furthermore, the difference between the two probabilities increases with the length of the transition period, ranging from 0.07 for 24 months, to 0.08 for 30 months, to 0.09 for 36 and 42 months.

\section{Insert Table 2}

Trying to answer directly our main question on the effects of innovation on survival we compare, within the CIS, the survival probabilities between innovators

\footnotetext{
${ }^{2}$ Among the European participants to the CIS, only the surveys for the UK and the Netherlands have set the threshold at 10 employees, while all the other countries have set it at 20 employees.
} 
and non-innovators. The survival probability of innovators is persistently higher than the one of non-innovators. The difference is on average equal to 3.6 per cent across all the four transition periods considered and statistically significant at 1 per cent. This is a first result, at very aggregate level, of the positive effect of innovation on survival.

In the CIS, there is a high percentage of innovators as shown in Table 1 (2075 firms are innovators while 1200 are non-innovators). This might be due to two factors: one, there could be an overestimation of the perception by the respondent to consider himself an innovator; second, the innovators are more likely to respond to the survey than non-innovators. This would suggest that the CIS tends to capture the majority of innovators. Indeed, the survival probability in BR without CIS records is lower than the probability for the entire BR with more than 10 employees (which represents the threshold of the CIS sample). This difference is statistically significant and equal to 0.02 and is persistent along time (24, 30, 36 and 42 months). There is thus evidence of a self-selection problem in the innovation survey: if this were not the case, the two probabilities should have been the same. This is a further indication of the effect of innovation on survival.

\subsection{Patterns by age and size}

The results of the analysis of the survival probabilities by age and size classes are shown in Table 3. Controlling for age and size, independently of each other, innovation has a positive effect on the survival probability. In fact, Tables 3 a shows that the difference in probability between innovators and non-innovators is on average equal to 3 per cent for small and medium firms and equal to 2 per cent for large ones. These differences are also persistent over time. Specifically, the highest survival probabilities are observed for medium firms, either in the group of innovators or noninnovators. Small firms are those with the lowest survival probabilities among noninnovators. However, among innovators the probability of survival of small firms is higher than that of large firms. In sum, small firms benefit most of innovation for their survival.

\section{Insert Table 3}

With regard to age class (Table $3 \mathrm{~b}$ ), the differences between innovators and noninnovators in survival probability become more pronounced than observed for size classes. The effect of innovation on average amounts to 6 per cent for young firms, to 
5 per cent for grown-up firms and to 3 per cent for old firms. The differences are statistically significant at 1 per cent level across all the transition periods, and increase over time. Overall, innovation appears to be more important for the survival of young firms.

As expected, old firms are those with the highest survival probability either among innovators or non-innovators. To the other extreme, young firms always display the lowest probability of survival. However, the gap between young and old firms decreases when considering the group of innovators. Among innovators, young firms have a survival probability 6 per cent lower than large firms, ranging from 5 per cent in 24 months to 7 per cent in 42 months. Among non-innovators, the difference is 8 per cent on average, increasing from 6 per cent in 24 months to 10 per cent in 42 months. All these differences are statistically significant at 1 per cent level. Grown-up firms are more similar in terms of probability of survival to old firms than to young firms, especially in the group of innovators, for which the difference is marginal.

\subsection{Interactive effect of age and size}

The literature tells us that not only the probability of survival increases with the size and age of a firm but that the two variables exert a positive interactive effect on it. To control for this interactive effect we calculate the survival probabilities for cross-tabulation of age and size classes. These are illustrated in Figures 1 and 2 respectively for innovators and non-innovators. Our results confirm earlier evidence for the set of non-innovators. Indeed, the probability of survival of the young and small firms is always the smallest probability among all classes and regardless of the transition periods. Looking at the young firms across different size classes, we observe that the probability to survive of these firms increases remarkably with the size (with an increment between 8 and 15 percent) in all transition periods. Among young firms, the survival probability of small firms is significantly lower than that of medium and large firms, at 1 per cent significance level, while the difference between medium and large firms is not statistically significant, also at 10 per cent level. On the other hand, looking at the small firms across different age classes, we note that the probability to survive increases with the age of the firm (between 10 and 19 percent). In this case, all the differences across age classes are statistically significant at 1 per cent level. 


\section{Insert Figure 1 and Figure 2}

In contrast our results does not support the evidence from the literature of a positive relationship between the survival of firms and the age and size of the firm for the set of innovators. Repeating the same analysis for innovators, we notice first of all that the survival probability of young and small firms is no longer the smallest among classes in any transition period. Indeed, it is equal or even slightly larger than the survival probability of large and old firms, which from the literature are expected to have the highest survival probability. Furthermore, the difference is not statistically significant, even at the 10 per cent level. On the contrary, for the sample of noninnovators the latter is always higher than the former of about on average 15 per cent and statistically significant, at 1 per cent level, across all the transition periods.

Conditional on the size class of small firms, the probability of survival is invariant across age classes in every transition period (all the differences are not statistically significant at 10 per cent level). On the other hand, conditional on the age class of young firms, the survival probability decreases with the size class (between 3 and 7 percent) independent of the transition period (the differences for small firms with respect to medium and large firms are statistically significant at 1 per cent level, while the difference between medium and large firm is mostly not significant). This trend is opposite to that observed for the non-innovators. A possible interpretation of this result is that young and small innovators enter the market with more novel ideas (leading to more radical innovations?) than similar firms entering with a large scale of production. It is known from the literature that different types of entry occur at a different size at the moment of entry. Greenfield entries are generally associated with smaller size than entries via diversification of existing firms. We then argue that young and small firms are start-ups that enter on an innovative idea, while young and medium-large firms are those that are created in the process of diversification of existing firms (providing the resources necessary to enter on a larger scale) and that are more likely to introduce incremental or less radical innovations. Our results suggest that for this second category of entrants, innovation is less important for survival than for start-ups. In sum, our results show that among young firms innovation is especially important for the survival of small firms compared to medium and large firms. 
In general, the survival probability of innovators is higher than that of noninnovators unconditional on size and age classes. ${ }^{3}$ Therefore, innovation has a positive effect on the probability to survive after controlling for size and age differences. For example, considering the longest time period, we observe that the probabilities for non-innovators and innovators are respectively equal to 0.75 and 0.93 for young and small (23 per cent difference, significant at 1 per cent), 0.88 and 0.96 for grown-up and medium firms ( 8 per cent difference, significant at 1 percent) and 0.88 and 0.91 for old and large firms ( 4 per cent difference, significant at 5 per cent). Across the all combinations of age and size classes, only the differences between innovators and non-innovators in the category of young and medium firms and of young and large firms are not statistically significant at 10 per cent level.

This positive effect increases on the long term. In general, the probabilities of innovators and non-innovators diverge as time lengthens. A possible interpretation is that firms do innovate especially to overcome the selection process in the market and survive in the long term, instead of just pursuing temporary monopoly profits. As shown in Figures 1 and 2, the differences between the survival probability of innovators and non innovators increases over time: for example, for young and small firms, it increased from 0.12 for 24 months, to 0.14 for 30 months and to 0.17 for 36 and 42 months. For grown-up and medium firms, it increases from 0.05 , to 0.06 and then to 0.07 . For the old and large firms these differences are almost invariant over time.

\subsection{Sectoral patterns}

Looking at the survival probabilities at sectoral level, we observe that in general innovation has a positive effect on firm survival. This effect increases with the length of the transition period. As shown in Figures 3 and 4, the differences between the probabilities for innovators and non-innovators are larger for the transition period of 42 months than for the transition period of 24 months. As also observed at the aggregate level, innovation tends to be more important for survival in the longer term within each one sector.

\footnotetext{
${ }^{3}$ The only exception is the case of grown-up and large firms in which the non-innovator probability is equal to 1 while the innovator probability is equal to 0.97 . This is probably due to the small number problem because there are only 7 firms in this class within the group of non-innovators.
} 
Across sectors, we observe a great deal of heterogeneity in the effects of innovation on the probability of survival. Not only the effect varies in intensity, from a minimum of 0 to a maximum of 15 per cent, but also in the direction. While the effect is positive and statistically significant (at 1 per cent level) in most cases, it is negative and statistically significant (at 1 and 5 per cent) in three sectors, namely publishing, chemicals, and instruments.

A possible interpretation for the publishing sector is that this sector is dominated by very large firms in the Netherlands (such as Kluwer, Elsevier and Vnu). These firms have undergone an intense process of acquisitions during the fifth worldwide wave of mergers and acquisitions, 1996-2000 (Schenk, 2002). This process has involved the acquisition of smaller (compared to the acquiring firms) and innovative firms. This results in a number of exits from our database of innovative firms, since they have lost their legal identity. As a consequence, these exits lower considerably the survival probability of innovators.

The chemical sector is the one for which the negative difference is the most pronounced. In the Netherlands, this sector is mainly constituted of bulk chemicals while pharmaceuticals is small and relatively less important. This composition of the sector implies that the chemical sector as a whole shares the characteristics of the bulk chemicals more than those of pharmaceuticals. Traditional bulk chemicals largely exploit economies of scale in producing mature and basic products. This may lead to a minor role of innovation in shaping the survival probability of firms.

Focusing on the sectors for which we find a positive effect, this effect is the largest in leather (15 per cent); electrical-electronics, pulp and paper and textiles (13 per cent); and machinery (10 per cent). These sectors belong to different technological groups. On one side, there are low-tech industries such as pulp and paper, leather and textiles. These are industries at the mature stage of the product life cycle (Klepper, 1996). At this stage the industry has undergone a shakeout and only the most efficient firms survived. Therefore innovations, which occur mainly in the production processes, are crucial for the existence itself of the firm (innovation is a necessary condition to survive in the market). On the other side, there are high-tech industries such as machinery and electrical-electronics, which are at the stage of expansion of 
the product life cycle. At this stage, firms compete by introducing new products and consequently innovation plays a major role.

In general heterogeneity across sectors is expected (Marsili, 2001). When we analyse the effects of innovation on survival controlling for sectors and an additional dimension, size or age of the firm, we notice that the patterns of these effects differ across sectors. Looking at the graphs of the survival probabilities by age across sectors, and by size across sectors, we found a broad variety of patterns with distinctive characteristics. Figures $5 \mathrm{a}$ and $5 \mathrm{~b}$ illustrate this diversity of patterns. The chemicals sector (Figure 5a), as previously observed, displays a rather distinctive pattern. In the classes of relatively small and old firms, non-innovators are more likely to survive than innovators. In contrast, innovation increases the probability of survival of large firms. In electrical-electronics (Figure 5b), innovation has generally a positive effect on the probability of survival across size and age classes. This effect is more evident in large and long established firms.

\section{Insert Figure $5 a$ and Figure $5 b$}

In sum, by controlling for sector differences, it is not possible to define any type of relationship between innovation and survival. The effects of innovation on survival can be either positive or negative or non-linear depending on the sector. Furthermore, no relationship can be established between survival and size and between survival and age. Thus, industrial sectors shape not only the relationship between innovation and survival, but also the well-established relationship between survival, size and age. The dominant technological characteristics in a sector are the driving forces for the survival of firms, more than the firm-specific characteristics as age and size.

\section{Conclusions}

In this paper, we analysed the relationship between innovation and survival of manufacturing firms using micro-economic databases from two different sources: the Business Register of the population of firms in the Netherlands and the Second Community Innovation Survey. In general we found that innovation matters for increasing the survival probability of firms. This effect becomes more pronounced as we examine the survival over longer time periods, from two years to three and half years. 
We then controlled for firm specific characteristics such as size and age that have been previously found to be important for shaping the survival of firms. The effects of innovation are especially important for the classes of small and young firms. These are the classes of firms that are generally identified in the literature as the most exposed to the risk of exit. Indeed for small, young and non-innovative firms, the survival probability is the lowest when compared to all the other classes. In contrast, for small, young and innovative firms this probability is comparable to other size and age classes of innovative firms, and it is always higher that the probability of noninnovators, unconditional on age and size. Innovation increases the survival probability of the young and small firms of 23 percent. 
Table 1. Descriptive statistics of the number of employees of manufacturing firms at 1996 by sample

\begin{tabular}{lrrrrrr}
\hline & $\mathrm{N}$ & Mean & Std Dev & Kurtosis & Skewness & Median \\
\hline All firms in BR & 60792 & 16.7 & 197.4 & 24648.7 & 133.8 & 2 \\
All firms in BR with at least 10 employees & 12260 & 74.1 & 434.9 & 5157.6 & 61.7 & 23 \\
All firms in BR with at least 10 employees not in CIS-2 & 9036 & 58.1 & 480.7 & 4694.5 & 61.5 & 19 \\
All firms in CIS-2 & 3275 & 117.2 & 261.0 & 112.0 & 9.0 & 54 \\
Innovators in CIS-2 & 2075 & 139.5 & 280.6 & 83.6 & 7.8 & 68 \\
Non innovators in CIS-2 & 1200 & 78.5 & 217.9 & 230.1 & 13.2 & 35 \\
\hline
\end{tabular}

Note:

Datasets: Business Register (BR), Second Community Innovation Survey (CIS-2). 
Table 2. Survival probabilities of firms by sample and transition period

\begin{tabular}{lrrrr}
\hline & \multicolumn{4}{c}{ Number of months } \\
\cline { 2 - 5 } & 24 & 30 & 36 & 42 \\
\hline All firms in BR & 0.85 & 0.82 & 0.79 & 0.77 \\
All firms in BR with at least 10 employees & 0.92 & 0.90 & 0.88 & 0.86 \\
All firms in BR with at least 10 employees not in CIS-2 & 0.90 & 0.88 & 0.86 & 0.84 \\
All firms in CIS-2 & 0.95 & 0.93 & 0.92 & 0.91 \\
Innovators in CIS-2 & 0.96 & 0.94 & 0.93 & 0.93 \\
Non innovators in CIS-2 & 0.93 & 0.91 & 0.90 & 0.89 \\
\hline
\end{tabular}

Note:

Datasets: Business Register (BR), Second Community Innovation Survey (CIS-2). 
Table 3a. Survival probabilities of innovators and non-innovators by size class and transition period

\begin{tabular}{|c|c|c|c|c|c|c|c|c|}
\hline \multirow[b]{3}{*}{ Size class } & \multicolumn{4}{|c|}{ Innovators } & \multicolumn{4}{|c|}{ Non-innovators } \\
\hline & \multicolumn{4}{|c|}{ Number of months } & \multicolumn{4}{|c|}{ Number of months } \\
\hline & 24 & 30 & 36 & 42 & 24 & 30 & 36 & 42 \\
\hline Small & 0.95 & 0.94 & 0.93 & 0.92 & 0.93 & 0.91 & 0.90 & 0.89 \\
\hline Medium & 0.96 & 0.95 & 0.95 & 0.94 & 0.94 & 0.93 & 0.92 & 0.91 \\
\hline Large & 0.95 & 0.93 & 0.92 & 0.91 & 0.93 & 0.92 & 0.90 & 0.88 \\
\hline
\end{tabular}

Table 3b. Survival probabilities of innovators and non-innovators by age class and transition period

\begin{tabular}{|c|c|c|c|c|c|c|c|c|}
\hline \multirow[b]{3}{*}{ Age class } & \multicolumn{4}{|c|}{ Innovators } & \multicolumn{4}{|c|}{ Non-innovators } \\
\hline & \multicolumn{4}{|c|}{ Number of months } & \multicolumn{4}{|c|}{ Number of months } \\
\hline & 24 & 30 & 36 & 42 & 24 & 30 & 36 & 42 \\
\hline Young & 0.92 & 0.90 & 0.88 & 0.87 & 0.88 & 0.85 & 0.83 & 0.81 \\
\hline Grown-up & 0.96 & 0.95 & 0.93 & 0.92 & 0.92 & 0.90 & 0.89 & 0.88 \\
\hline Old & 0.96 & 0.95 & 0.94 & 0.93 & 0.94 & 0.92 & 0.91 & 0.90 \\
\hline
\end{tabular}


Figure 1. Survival probabilities of innovators by size class and age class for different transition periods

Small

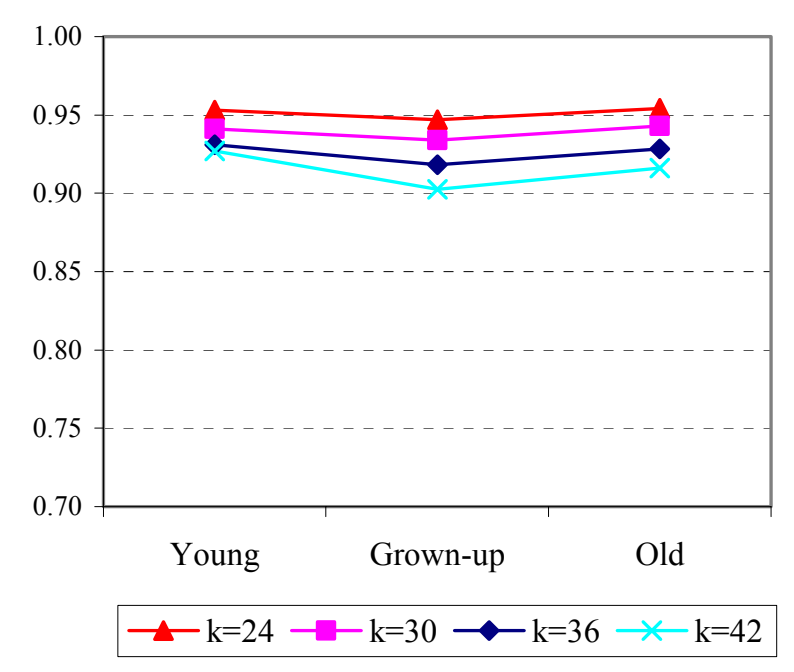

Medium

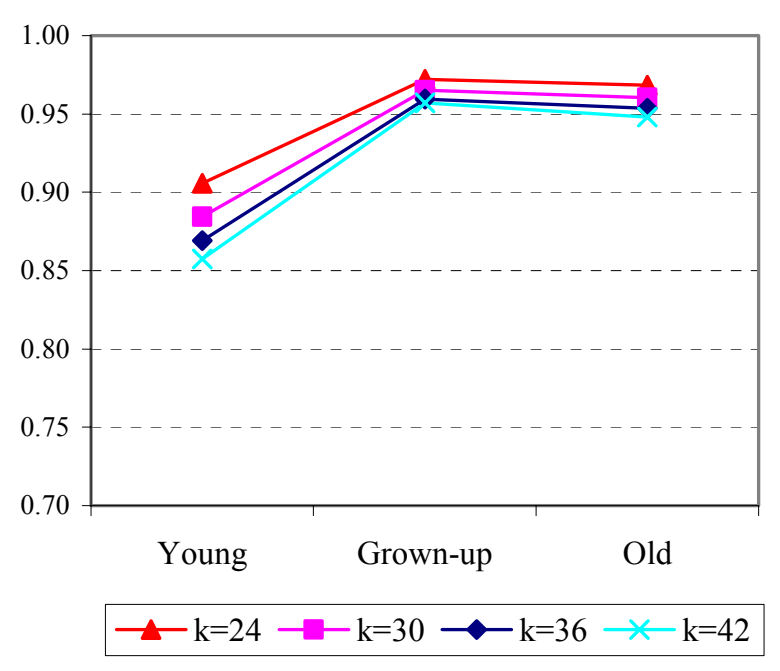

Large

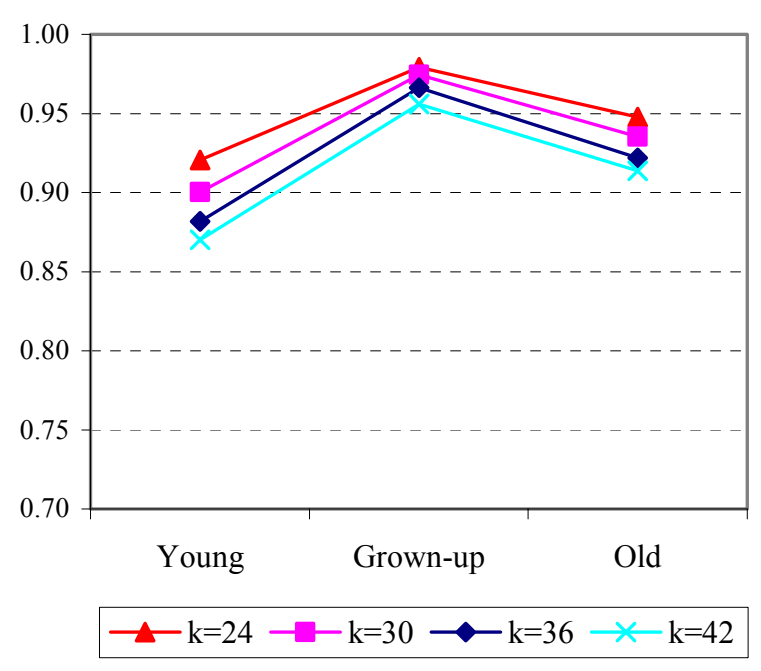

Figure 2. Survival probabilities of non-innovators by size class and age class for different transition periods

Small

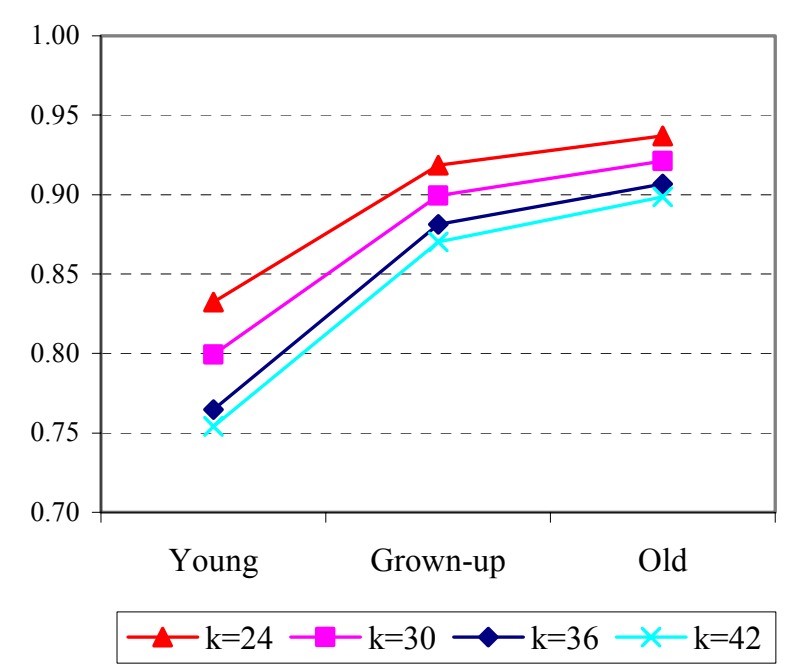

Medium

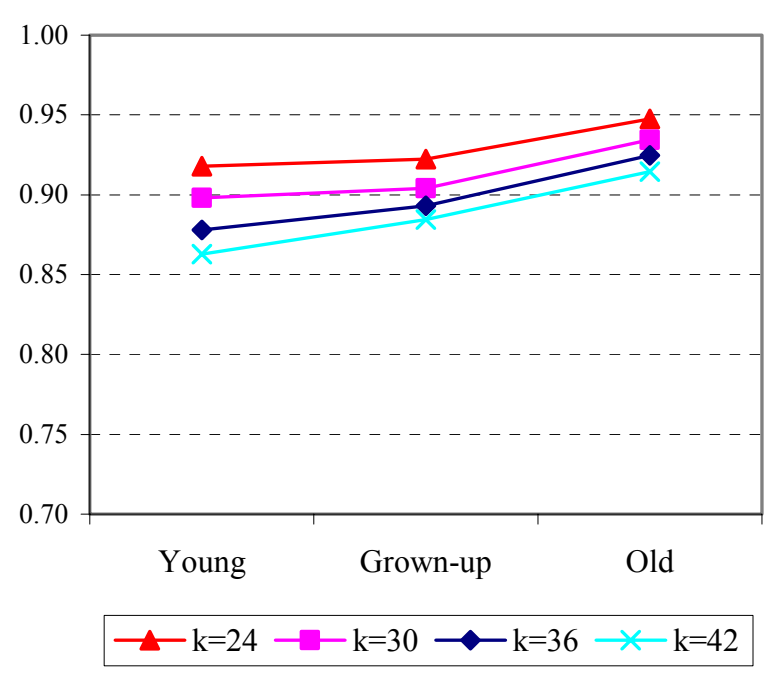

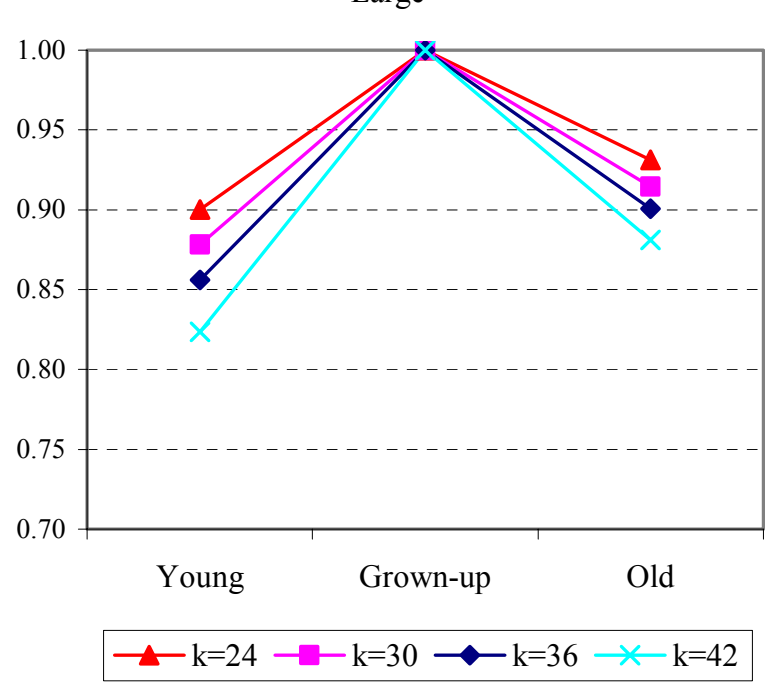


Figure 3. Survival probabilities of innovators and non-innovators by sector (transition period of 24 months)

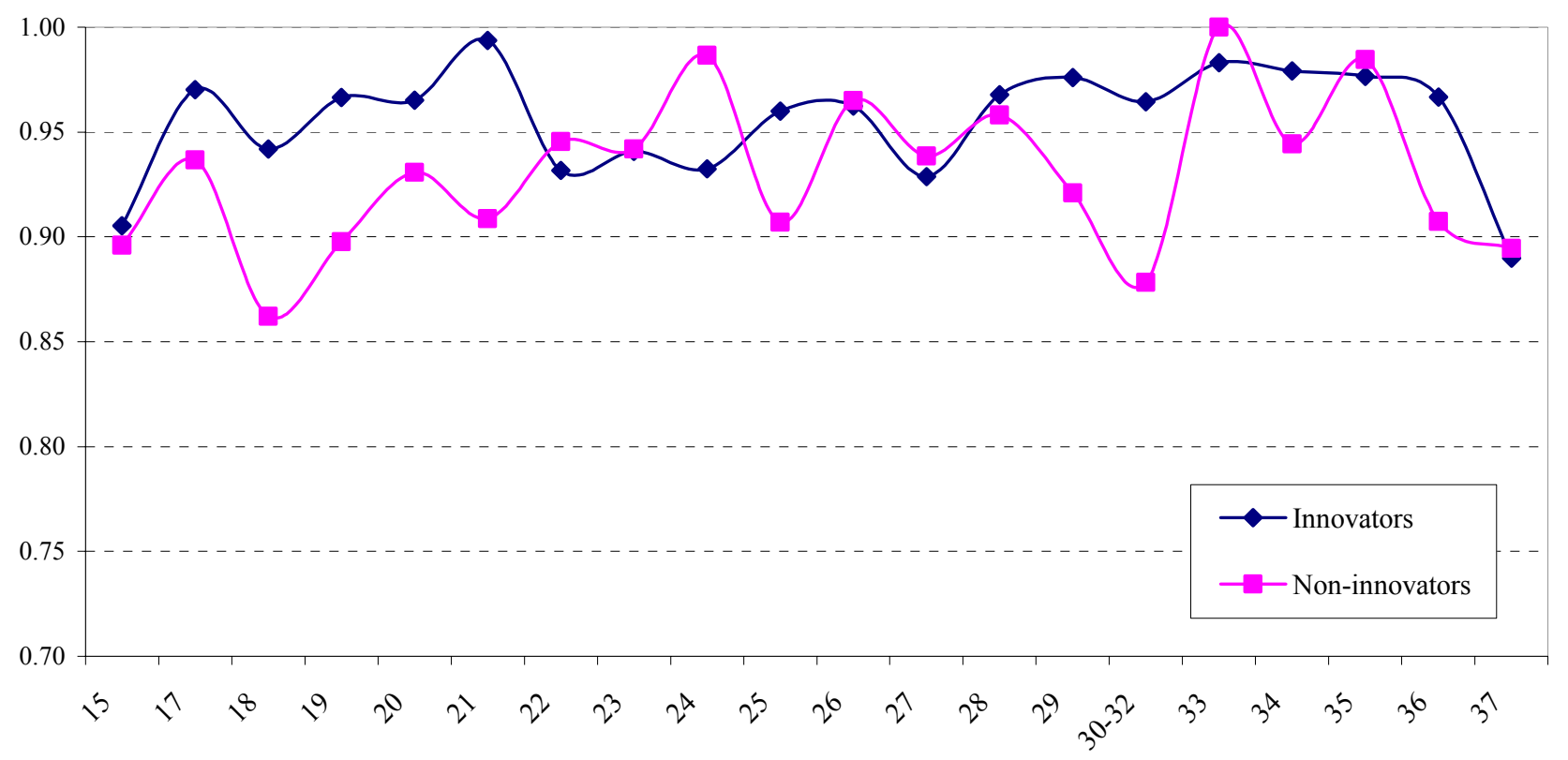

Figure 4. Survival probabilities of innovators and non-innovators by sector (transition period of 42 months)

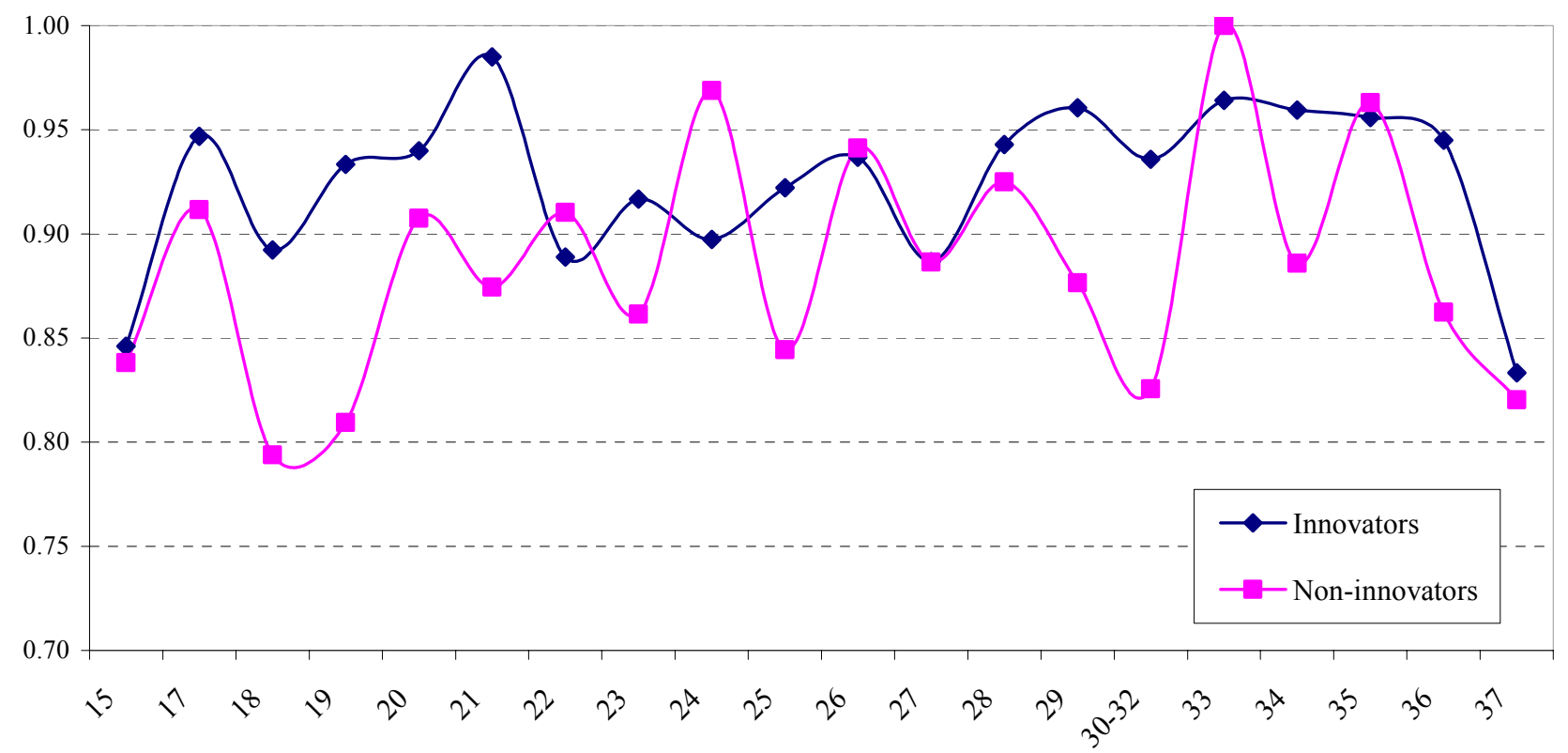


Figure 5a. Survival probabilities by size and age class by sector: Chemicals
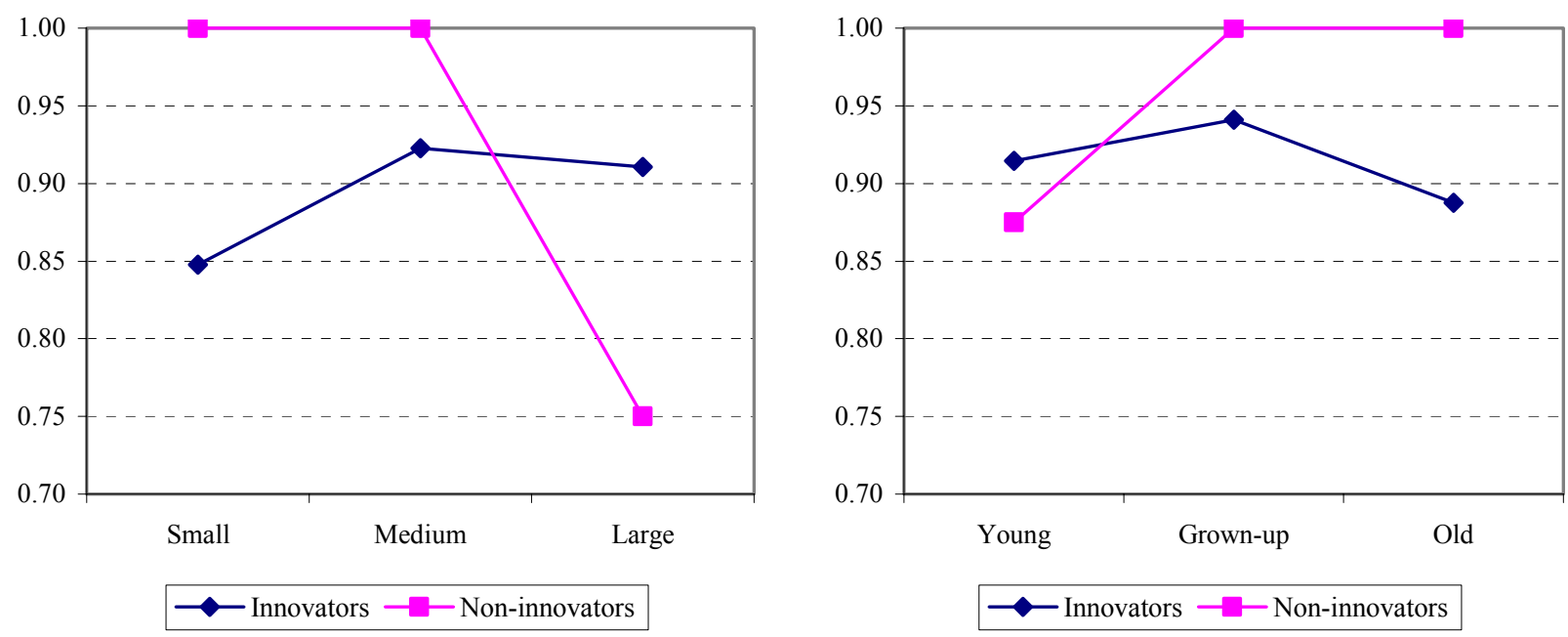

Figure 5b. Survival probabilities by size and age class by sector: Electrical-electronics
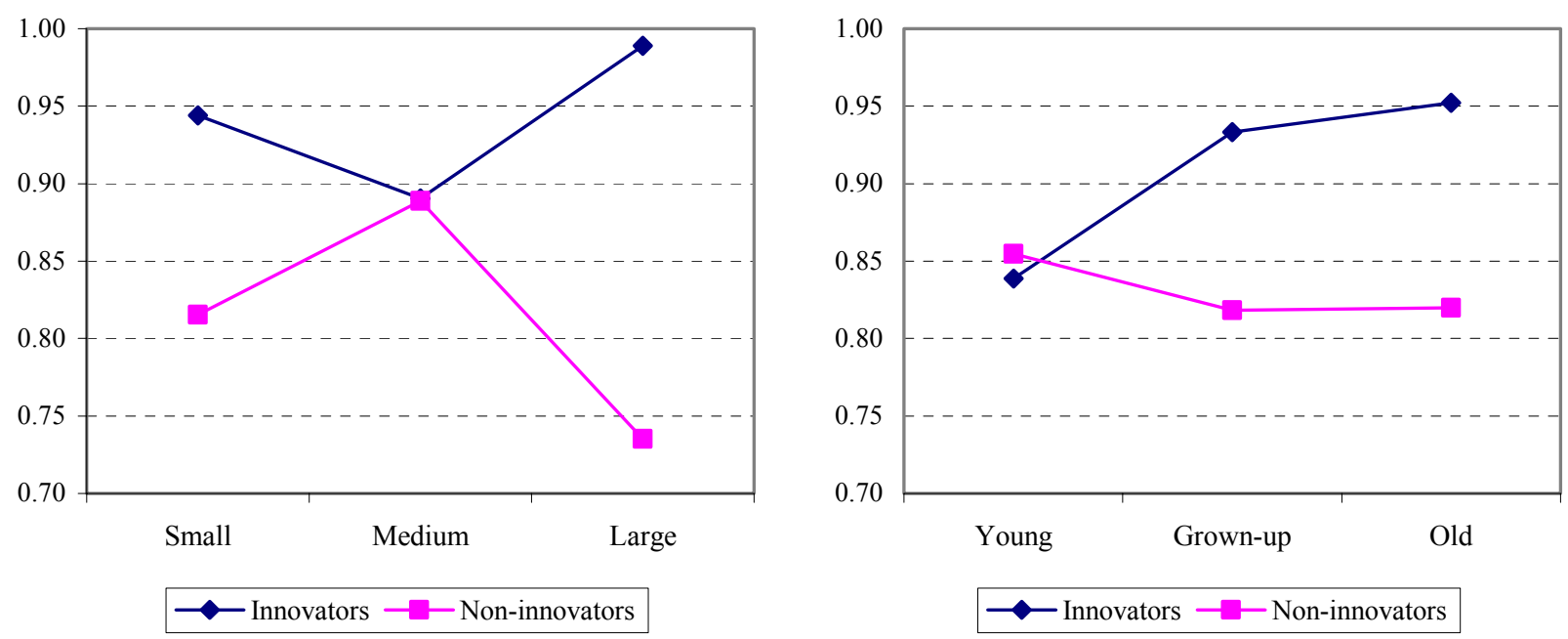


\section{Appendix}

Table I. Industrial sectors

\begin{tabular}{lll}
\hline Code & Sector & NACE Rev.1 Description \\
\hline 15 & Food & Manufacture of food products and beverages \\
16 & Tobacco & Manufacture of tobacco products \\
17 & Textiles & Manufacture of textiles \\
18 & Apparel & Manufacture of wearing apparel; dressing and dyeing of fur \\
19 & Leather & Tanning and dressing of leather; manufacture of luggage, handbags, saddlery, \\
& & harness and footwear \\
20 & Wood & Manufacture of wood and of products of wood and cork, except furniture; \\
& & manufacture of articles of straw and plaiting materials \\
21 & Pulp and paper & Manufacture of pulp, paper and paper products \\
22 & Publishing & Publishing, printing and reproduction of recorded media \\
23 & Petroleum & Manufacture of coke, refined petroleum products and nuclear fuel \\
24 & Chemicals & Manufacture of chemicals and chemical products \\
25 & Rubber and plastics & Manufacture of rubber and plastic products \\
26 & Mineral products & Manufacture of other non-metallic mineral products \\
27 & Basic metals & Manufacture of basic metals \\
28 & Metal products & Manufacture of fabricated metal products, except machinery and equipment \\
29 & Machinery & Manufacture of machinery and equipment n.e.c. \\
30 & Computers & Manufacture of office machinery and computers \\
31 & Electrical equipment & Manufacture of electrical machinery and apparatus n.e.c. \\
32 & Telecommunications & Manufacture of radio, television and communication equipment and apparatus \\
33 & Instruments & Manufacture of medical, precision and optical instruments, watches and clocks \\
34 & Automobile & Manufacture of motor vehicles, trailers and semi-trailers \\
35 & Other transportation & Manufacture of other transport equipment \\
36 & Other manufacturing & Manufacture of furniture; manufacturing n.e.c. \\
37 & Recycling & Recycling \\
\hline
\end{tabular}


Table II. Values of the $\mathrm{Z}$ statistic for comparison between probabilities

\begin{tabular}{|c|c|c|c|c|}
\hline \multirow{2}{*}{ Comparison groups } & \multicolumn{4}{|c|}{ Number of months } \\
\hline & 24 & 30 & 36 & 42 \\
\hline BR vs. BR with at least 10 employees & $-102.1 * * *$ & $-100.9 * * *$ & $-92.2 * * *$ & $-78.4 * * *$ \\
\hline Innovators vs. non-innovators in CIS-2 & $17.4^{* * *}$ & $17.3^{* * *}$ & $15.5 * * *$ & $12.6^{* * *}$ \\
\hline BR not in CIS-2 vs. BR ( $\geq 10$ empl.) & $-16.8 * * *$ & $-16.5 * * *$ & $-15.9 * * *$ & $-14.3 * * *$ \\
\hline \multicolumn{5}{|l|}{ Innovators vs. non innovators (Table 3a) } \\
\hline Small & $10.5^{* * *}$ & $10.5^{* * *}$ & $8.7 * * *$ & $6.0 * * *$ \\
\hline Medium & $9.1 * * *$ & $9.1 * * *$ & $8.5 * * *$ & $7.7 * * *$ \\
\hline Large & $2.5^{* *}$ & $2.4^{* *}$ & $2.0^{* *}$ & $2.6^{* * *}$ \\
\hline \multicolumn{5}{|l|}{ Innovators vs. non innovators } \\
\hline Young & $5.7 * * *$ & $5.4 * * *$ & $5.4 * * *$ & $4.7 * * *$ \\
\hline Grown-up & $7.7 * * *$ & $7.6 * * *$ & $6.4 * * *$ & $4.9 * * *$ \\
\hline Old & $15.4^{* * *}$ & $15.5^{* * *}$ & $13.8 * * *$ & $11.1 * * *$ \\
\hline \multicolumn{5}{|l|}{ Small vs. large firms } \\
\hline Innovators & $3.1 * * *$ & $3.2 * * *$ & $2.3^{* *}$ & 1.1 \\
\hline Non-innovators & -0.4 & -0.4 & -0.5 & 0.7 \\
\hline \multicolumn{5}{|l|}{ Young vs. old firms } \\
\hline Innovators & $-15.3 * * *$ & $-15.2 * * *$ & $-13.2 * * *$ & $-10.4 * * *$ \\
\hline Non-innovators & $-11.2 * * *$ & $-10.7 * * *$ & $-10.1 * * *$ & $-8.5^{* * *}$ \\
\hline \multicolumn{5}{|l|}{ Firms across size classes $(\mathrm{S}, \mathrm{M}, \mathrm{L})$} \\
\hline \multicolumn{5}{|l|}{$\begin{array}{l}\mathrm{S} / \mathrm{M} \\
\end{array}$} \\
\hline Young innovators & $5.3 * * *$ & $4.7 * * *$ & $4.8 * * *$ & $5.3 * * *$ \\
\hline Young non-innovators & $-6.3 * * *$ & $-6.0 * * *$ & $-5.5^{* * *}$ & $-4.2 * * *$ \\
\hline \multicolumn{5}{|l|}{$\mathrm{M} / \mathrm{L}$} \\
\hline Young innovators & $-1.8^{*}$ & -0.9 & -0.7 & -0.7 \\
\hline Young non-innovators & 1.2 & 1.1 & 0.9 & 1.3 \\
\hline \multicolumn{5}{|l|}{$\mathrm{S} / \mathrm{L}$} \\
\hline Young innovators & $3.7 * * *$ & $2.8 * * *$ & $3.2 * * *$ & $3.6^{* * *}$ \\
\hline Young non-innovators & $-3.5 * * *$ & $-3.4 * * *$ & $-3.2 * * *$ & $-1.9 *$ \\
\hline \multicolumn{5}{|l|}{ Firms across age classes $(\mathrm{Y}, \mathrm{G}, \mathrm{O})$} \\
\hline \multicolumn{5}{|l|}{$\overline{\mathrm{Y} / \mathrm{G}}$} \\
\hline Small innovators & 0.9 & 0.8 & 1.1 & 1.6 \\
\hline Small non-innovators & $-7.5 * * *$ & $-7.2 * * *$ & $-6.8 * * *$ & $-5.3 * * *$ \\
\hline \multicolumn{5}{|l|}{$\mathrm{G} / \mathrm{O}$} \\
\hline Small innovators & $-1.7 *$ & $-1.7^{*}$ & -1.5 & -1.5 \\
\hline Small non-innovators & $-3.5 * * *$ & $-3.3 * * *$ & $-3.1 * * *$ & $-2.7 * * *$ \\
\hline \multicolumn{5}{|l|}{$\mathrm{Y} / \mathrm{O}$} \\
\hline Small innovators & -0.2 & -0.3 & 0.3 & 0.9 \\
\hline Small non-innovators & $-12.8 * * *$ & $-12.1 * * *$ & $-11.3 * * *$ & $-9.1 * * *$ \\
\hline \multicolumn{5}{|l|}{ Small and young vs. Large and old } \\
\hline Innovators & 0.8 & 0.6 & 0.8 & 1.2 \\
\hline Non-innovators & $-8.0 * * *$ & $-7.6^{* * *}$ & $-7.3 * * *$ & $-5.3 * * *$ \\
\hline
\end{tabular}

Notes:

*** statistically significant at 1 per cent

** statistically significant at 5 per cent

* statistically significant at 10 per cent 
Table II (continues). Values of the $\mathrm{Z}$ statistic for comparison between probabilities

\begin{tabular}{|c|c|c|c|c|}
\hline \multirow{2}{*}{ Comparison groups } & \multicolumn{4}{|c|}{ Number of months } \\
\hline & 24 & 30 & 36 & 42 \\
\hline \multicolumn{5}{|c|}{ Innovators vs. non-innovators } \\
\hline \multicolumn{5}{|l|}{ Small firms } \\
\hline Young & $9.7 * * *$ & $9.2 * * *$ & $9.6 * * *$ & $9.0^{* * * *}$ \\
\hline Grown-up & $4.1 * * *$ & $4.2 * * *$ & $3.8^{* * *}$ & $2.8^{* * *}$ \\
\hline Old & $7.3 * * *$ & $7.7 * * *$ & $6.5^{* * *}$ & $4.4 * * *$ \\
\hline \multicolumn{5}{|l|}{ Medium firms } \\
\hline Young & -1.3 & -1.1 & -0.6 & -0.3 \\
\hline Grown-up & $6.7 * * *$ & $5.4^{* * *}$ & $5.3 * * *$ & $5.1 * * *$ \\
\hline Old & $8.9 * * *$ & $7.5 * * *$ & $7.4 * * *$ & $7.2 * * *$ \\
\hline \multicolumn{5}{|l|}{ Large firms } \\
\hline Young & 1.5 & 1.0 & 1.0 & 1.6 \\
\hline Grown-up & $-2.1 * *$ & $-2.1 * *$ & $-2.1 * *$ & $-2.0^{* *}$ \\
\hline Old & $2.6 * * *$ & $2.1 * *$ & $1.9 * *$ & $2.4 * *$ \\
\hline
\end{tabular}

Table III. Values of the $\mathrm{Z}$ statistic for comparison between probabilities

\begin{tabular}{clrr}
\hline \multirow{2}{*}{ Comparison groups } & \multicolumn{2}{c}{ Number of months } \\
\cline { 2 - 4 } Innovators vs. non-innovators & \multicolumn{2}{c}{42} \\
\hline SIC & Sector & 1.6 & 0.7 \\
15 & Food & $4.9^{* * *}$ & $2.6^{* * *}$ \\
17 & Textiles & $5.7^{* * *}$ & $3.7^{* * *}$ \\
18 & Apparel & $4.3^{* * *}$ & $3.7^{* * *}$ \\
19 & Leather & $4.5^{* * *}$ & $2.2^{* *}$ \\
20 & Wood & $13.5^{* * *}$ & $9.2^{* * *}$ \\
21 & Pulp and paper & $-2.7^{* * *}$ & $-2.2^{* *}$ \\
22 & Publishing & 0.0 & 1.2 \\
23 & Petroleum & $-6.5^{* * *}$ & $-4.4^{* * *}$ \\
24 & Chemicals & $7.4^{* * *}$ & $5.2^{* * *}$ \\
25 & Rubber and plastics & -0.4 & -0.4 \\
26 & Mineral products & -0.8 & 0.0 \\
27 & Basic metals & $2.8^{* * *}$ & $2.5^{* *}$ \\
28 & Metal products & $13.3^{* * *}$ & $10.3^{* * *}$ \\
29 & Machinery & $11.6^{* * *}$ & $7.6^{* * *}$ \\
$30-32$ & Electrical-electronics & $-4.1^{* * *}$ & $-3.8^{* * *}$ \\
33 & Instruments & $5.2^{* * *}$ & $5.0^{* * *}$ \\
34 & Automobile & $-1.7^{*}$ & -0.7 \\
35 & Other transportation & $8.8^{* * *}$ & $6.3^{* * *}$ \\
36 & Other manufacturing & -0.2 & 0.3 \\
37 & Recycling & &
\end{tabular}

Notes: See Table II 


\section{References}

Agarwal, R. and D. B. Audretsch, 2001, "Does Entry Size Matter? The Impact of the Life Cycle and Technology on Firm Survival", The Journal of Industrial Economics, 49(1), pp. 21-43.

Audretsch, D. B., 1995, "Innovation, Growth and Survival", International Journal of Industrial Organization, 13(4), pp. 441-457.

Audretsch, D. B., 1997, "Technological Regimes, Industrial Demography and the Evolution of Industrial Structures", Industrial and Corporate Change, 6(1), pp. 49-82.

Baumol, W. J., 2002, Free Market Innovation Machine: Analyzing the Growth Miracle of Capitalism. Princeton Univ Press.

Cefis, E., 2003, “Is there any Persistence in Innovative Activites?”, International Journal of Industrial Organization, 21(4), pp 489-515.

Christensen, C. M., F. F. Suarez and J. M. Utterback, 1998, "Strategies for Survival in FastChanging Industries", Management Science, 44(12, Part 2 of 2), pp. S207-S220.

Christensen, M. C., 1997, The Innovator's Dilemma. Harvard Business School Press.

Dunne, P. and A. Hughes, 1994, "Age, Size, Growth and Survival: Uk Companies in the 1980s", The Journal of Industrial Economics, 42(2), pp. 115-139.

Ericson, R. and A. Pakes, 1995, "Markov-Perfect Industry Dynamics: A Framework for Empirical Work", Review of Economic Studies, 62(1), pp. 53-82.

Evans, D. S., 1987, "The Relationship between Firm Growth, Size, and Age: Estimates for 100 Manufacturing Industries", The Journal of Industrial Economics, 35(4, The Empirical Renaissance in Industrial Economics), pp. 567-581.

Geroski, P. A., 1995, "What Do We Know About Entry?" International Journal of Industrial Organization, 13(4), pp. 421-440.

Hall, B. H., 1987, "The Relationship between Firm Size and Firm Growth in the Us Manufacturing Sector", The Journal of Industrial Economics, 35(4), pp. 583-606.

Jovanovic, B., 1982, "Selection and the Evolution of Industry", Econometrica, 50(3), pp. 649670.

Klepper, S., 1996, "Entry, Exit, Growth, and Innovation over the Product Life Cycle", The American Economic Review, 86(3), pp. 562-583.

Marsili, O., 2001, The Anatomy and Evolution of Industries, Cheltenham: Edward Elgar.. 
Mata, J. and P. Portugal, 1994, "Life Duration of New Firms", The Journal of Industrial Economics, 42(3), pp. 227-245.

Mata, J., P. Portugal and P. Guimaraes, 1995, "The Survival of New Plants: Start-up Conditions and Post-Entry Evolution", International Journal of Industrial Organization, 13(4), pp. 459-481.

Nelson, R. R. and S. G. Winter, 1982, An Evolutionary Theory of Economic Change. Cambridge, MA: Belknap Press of Harvard University Press.

Schenk, H., 2002, Mergers, Efficient Choice, and International Competitiveness. Bandwagon Behaviour and Industrial Policy Implications. Cheltenham: Edward Elgar.

Scherer, F. M., 1980, Industrial Market Structure and Economic Performance. Chicago: Rand McNally.

Schumpeter, J. A., 1942, Capitalism, Socialism and Democracy. New York: Harper \& Row. 